\title{
Tecnologia e comportamento humano: Um infinito de possibilidades
}

\section{Technology and human behavior: An infinity of possibilities}

Miguel Melo

EDITORIAL | EDITORIAL

A tecnologia está cada vez mais presente no nosso dia a dia, tornando-se incontornável a sua utilização. Sendo que o conceito de comportamento humano se refere, de forma geral, a um conjunto de reações face às interações de um indivíduo com o meio envolvente, percebe-se desde logo a estreita ligação entre os domínios da tecnologia e do comportamento humano.

A tecnologia tem evoluído de forma significativa, contribuindo para uma mudança de paradigmas a um nível transversal. De entre os vários campos tecnológicos, há que destacar o nível de maturidade que as tecnologias de Realidade Virtual alcançaram.

A Realidade Virtual pode ser definida como uma tecnologia que permite a simulação de ambientes virtuais onde os utilizadores podem interagir com os elementos virtuais que os constituem. Dada a natureza das tecnologias de Realidade Virtual, estas têm vindo a ser adotadas numa variedade de áreas de aplicação com o propósito de capacitar recursos humanos e, assim, aumentar o seu desempenho.

A título de exemplo, a Realidade Virtual na medicina tem sido utilizada para simular procedimentos médicos permitindo aos profissionais da área treinarem procedimentos médicos de uma forma realista que lhes permite uma maior qualidade no desempenho das suas atividades profissionais e, em última instância, salvar vidas. Na educação, a Realidade Virtual tem sido adotada como um meio de transmissão de conteúdos pedagógicos que provou ser mais apelativa para os educandos e que lhes confere mais facilidade na retenção de conhecimento. Já na indústria, as tecnologias de Realidade Virtual têm beneficiado não só a otimização de processos como os progamas de treino. Os programas de treino a funcionários acarretam custos significativos às empresas quer seja pelos recursos necessários à realização dos cenários de treino, o tempo necessário para fornecer as competências para o trabalho, a replicabilidade ou a segurança dos formandos. A a adoção de tecnologias de Realidade Vitual permitem ultrapassar essas questões pois permitem a criação personalizada de ambientes de treino virtuais onde o ambiente de treino é totalmente controlado e onde as empresas têm controlo absoluto sobre o processo sem comprometer a operacionalidade da sua atividade.

Como acima descrito, é possível compreender que as tecnologias de Realidade Virtual, por si só, trazem um valor acrescentado a diferentes áreas de aplicação. Contudo, as tecnologias de Realidade Virtual podem ser alavancadas e abrirem portas a soluções ainda mais inovadoras e revolucionárias. Um exemplo concreto é a utilização de tecnologias 
de Realidade Virtual para terapias cognitivo-comportamentais revolucionárias no domínio da psicologia, nomeadamente em terapias de exposição para tratamento de perturbações de stress pós-traumático e de fobias.

O aparecimento da terapia virtual dá-se pela combinação das tecnologias de Realidade Virtual com três áreas de conhecimento distintas: técnicas de processamento digital de imagem, processamento de dados fisiológicos e técnicas de inteligência. Assim, para se obter um psicólogo virtual que consiga dar resposta às necessidades terapêuticas em cenários de perturbação de stress pós-traumático e de fobia, recorre-se à captura de imagem do paciente. As imagens capturadas são devidamente processadas utilizando técnicas de processamento digital de imagem que são capazes de fazer o reconhecimento de expressões faciais e corporais do paciente de forma a detetar emoções através da sua linguagem corporal. De forma complementar, são também capturados dados fisiológicos relativos à atividade cardíaca e respiratória de forma a obter mais dados sobre o seu estado psicológico tais como os níveis de ansiedade ou stress. Todos estes dados são cruzados e, com recurso a técnicas de inteligência artificial, é possível dotar o psicólogo virtual de inteligência necessária à condução, em tempo real, de uma sessão terapêutica baseada num guião que é respeitado face aos diferentes momentos da sessão e do estado psicológico do paciente.

O exemplo da utilização de Realidade Virtual na área Psicologia, nomeadamente através de terapia de exposição é um pequeno exemplo das potencialidades da tecnologia para proveito do ser humano. $\mathrm{Na}$ verdade, a Realidade Virtual é uma tecnologia onde os seus limites cruzam-se com os limites da imaginação humana. E, independentemente do domínio de aplicação, o único limite que se parece por aproveitamento da evolução tecnológica para benefício do ser humano é mesmo a criatividade humana.

(c) BY-NC Todo o conteúdo da revista PsychTech \& Health Journal está licenciado sob a Creative Commons, exceto quando especificado em contrário e nos conteúdos retirados de outras fontes bibliográficas. 